\title{
TERMINOLOGIA E ESTRUTURA CONCEITUAL
}

Terminologia-documentação-classificação. Os três pilares para a construção da rede internacional de informação

(E.Wüster).

\begin{abstract}
Resumo: A introdução da terminologia para representação de assuntos, em detrimento do tradicional cabeçalho de assunto, trouxe a classificação como base para a elaboração de instrumentos semânticos de representação do conhecimento. A Teoria Geral da Terminologia de Wüster, a Teoria de Classificação analítico-sintética de Ranganathan e a Teoria do Conceito de Dahlberg têm em comum o conceito e suas relações que produzem a estrutura sistemática de um domínio, áreas em que predomina a abordagem onomasiológica. As teorias servem para a elaboração de bancos de termos inteligentes e sua aplicação em tesauros, ontologias e terminologias.
\end{abstract}

Palavras-chave: Terminologia sistemática; teorias de classificação.

\section{TERMINOLOGY AND CONCEPTUAL STRUCTURE}

\begin{abstract}
The introduction of terminology for subject representation instead of the traditional subject headings, brought classification theory as the basis for the construction of semantic tools for knowledge representation. Wüster's General Theory of Terminology, Ranganathan's Analytico-Synthetic Classification and Dahlberg's Concept theory have concept and conceptual relations in common and these contribute to the production of the systematic structure of a knowledge domain, with the onomasiological approach. Those theories are fit for the elaboration of smart term banks and their application in thesauri, ontologies and terminologies.
\end{abstract}

Key words: Systematic terminology; Classification theories.

\section{COMEÇO}

O conceito "recuperação de informação" introduzido por Calvin Mooers nos anos 50 do século passado, resultou do uso da computação para recuperar informação através de busca direta nos textos. Dois aspectos revolucionaram os procedimentos bibliotecários: o abandono do cabeçalho de assunto e o conceito de recuperação: se nos cabeçalhos o assunto era estabelecido a-priori, de acordo com uma lista de assuntos preestabelecidos, na recuperação o assunto era representado por palavras que, coordenadas no momento da busca, representariam o assunto desejado - a posteriori. Se no modelo anterior havia uma sequência preestabelecida, no novo paradigma, qualquer ordem das palavras seria permitida no momento da busca. 
Surge um novo instrumento de controle de vocabulário intitulado "thesaurus", assim denominado por analogia com o clássico dicionário analógico de Roget. ${ }^{1}$ Nesse novo instrumento de indexação/recuperação subjaz um sistema de classificação.

Mas a unidade naquele momento era a palavra. A estratégia de busca trouxe o emprego da álgebra booleana, pretendendo-se com isso, minimizar os problemas advindos de palavras isoladas que são destituídas de sentido. Assim, a busca por "transferência de tecnologia", por exemplo, seria feita por duas palavras: "transferência" e "tecnologia", mas o resultado não garantiria sucesso, pois as palavras poderiam estar no texto, mas a representação do assunto não seria expressa apenas pela coordenação de palavras. O tempo mostrou que tal estratégia não resolvia o problema pois gerava, por vezes, ruído na recuperação. Se formos buscar o sentido da expressão, vamos perceber que, no caso, "transferência" foi utilizada metaforicamente, o que significa que o sentido não se obtém pela soma das palavras; então a unidade seria "transferência de tecnologia" que significa, de modo amplo, o processo de adquirir, de dominar uma certa habilidade técnica e métodos de uma dada tecnologia a ponto de poder replicá-la.

Nesse aspecto, o impacto da introdução da computação entre os bibliotecários foi negativamente surpreendente: o cabeçalho de assunto assegurava o sentido pretendido nas palavras ali presentes. Ao isolá-las como assegurar o significado pretendido? Afinal, nos primórdios, o sistema computacional só recuperava palavras únicas.

O Instituto Brasileiro de Bibliografia e Documentação (IBBD) realizava cursos de especialização: seu conteúdo incluía princípios de indexação e de construção do novo instrumento de controle de "vocabulário". A influência da língua inglesa na organização dos cabeçalhos de assunto ainda estava presente na norma americana de construção de tesauros. Era preciso encontrar alguma base teórica para a nova unidade, a saber, o termo. A Norma Internacional de Terminologia para Denominação - ISO 704 - fornecia os elementos para o novo instrumento de trabalho, a saber, a unidade era o conceito, representado pelo termo. Com a introdução deste elemento, desapareceram as preocupações com a questão lexical. Além disso, na norma estavam os elementos básicos para as relações entre conceitos, exatamente como proposto para os tesauros documentários: relacionamentos lógicos (abstratos, que produziriam a hierarquia) e ônticos, de contiguidade no espaço e no tempo (relações entre objetos, que produziriam as relações associativas, além das partitivas). Em encontro no IBBD

1 Roget, Mark. Thesaurus of English words and phrases, editado em 1852, mas com sucessivas impressões até os dias atuais. 
apresenta-se a norma de terminologia e sua pertinência na elaboração de tesauros (GOMES, 1970). Tal Norma teve sua origem nos estudos de Wüster, nas primeiras décadas do século XX e que resultaram na Teoria Geral da Terminologia publicada como tese e difundida em seus artigos. ${ }^{2}$ A norma apresentava princípios para a organização sistemática de pequenos campos conceituais, como uma rede semântica. A solução, a Biblioteconomia tinha, como revelou o tempo, solução para a organização daqueles campos em um todo consistente.

À mesma época, no âmbito da Biblioteconomia, Ranganathan (1967) publica a primeira edição de sua Teoria analítico-sintética, voltada para a elaboração de um código de classificação para biblioteca. A base teórica forneceu posteriormente os elementos para o novo instrumento de 'controle de vocabulário', a saber, o tesauro documentário, quando Aitchison (1968) produz o Thesaurofacet, com base nos princípios da Classificação analítico-sintética e suas Categorias Fundamentais.

Era preciso juntar as duas pontas: os conceitos (designados pelos termos) e o sistema de conceitos. A ideia não é nova. Wüster (1974) registra posteriormente algo que ainda se pode considerar atual: se de um lado os documentalistas que trabalham na elaboração de tesauros não estão suficientemente conscientes do fato que seus trabalhos têm um caráter linguístico, de outro, os linguistas não se interessam, na maioria das vezes, pela documentação. Daí que muitas vezes diferentes grupos de pessoas se debruçam sobre os mesmos problemas sem que se estabeleça entre eles comunicação suficiente (WÜSTER, 1974, 1981, p. 107). "Documentalistas e terminólogos precisam se unir numa pesquisa sobre a classificação onde se deve incluir naturalmente também o ponto de vista da classificação científica, da lógica e da teoria da ordenação" (WÜSTER, 1971, 1996, p. 145). Tal aproximação é ainda incipiente. Talvez a dificuldade se deva aos propósitos de cada grupo. Este parece ser o ponto essencial.

No entanto, a colaboração almejada não se dê entre a Linguística e a Documentação/Ciência da Informação, mas provavelmente entre Terminologia e Classificação.

2 Sua proposta está referenciada em diferentes momentos nesta comunicação.

3 Wüster refere-se a "documentação", devendo-se entender, no entanto, que ela corresponde a "ciência da informação" - expressão criada pelos norte-americanos -, mas nomeada ora "informação científica" no Reino Unido, ora "informática" na Europa e na União Soviética com a introdução da computação. Em um texto Wüster se refere explicitamente a informática, como nova ciência relacionando-a a thesaurus. Além disso ele estuda a CDU exaustivamente tornando evidente sua visão sobre a estreita relação entre as duas áreas de conhecimento 
A perspectiva adotada, neste estudo é demonstrar tal integração, tendo em vista que há alguns princípios comuns, válidos para diferentes propósitos. O texto está assim estruturado: o problema, abordagens metodológicas, o conceito, as relações conceituais, perspectivas futuras.

\section{O PROBLEMA}

A preocupação com a linguagem científica vem de longa data, desde Lineu, Lomonosov, e tantos outros. No século XIX, os avanços do conhecimento conhecidos como a segunda revolução tecnológica produziram novos conceitos e termos. No início do século XX alguns fatores vêm à tona no ambiente da ciência e da técnica, dentre outros a necessidade de produzir dicionários especializados trazendo a discussão, de um lado, para a organização sistemática, em detrimento da ordem alfabética dos dicionários, e, de outro, a necessidade de disciplinar o vocabulário científico-técnico, considerando que a formação natural dos termos era insuficiente para a comunicação científica e técnica devido à presença de fenômenos como polissemia, sinonímia e imprecisão. Além disso, considerando a importância de se produzir dicionários técnicos multilíngues o trabalho requeria arranjo sistemático, e não alfabético, e também o tratamento dos conceitos, dado que eles fazem parte de um sistema. Segundo Wüster, (1974, 1981), sua Teoria Geral da Terminologia (TGT) postulava o arranjo sistemático. Tal arranjo constituía um “auxílio apreciável” para a compreensão das definições, uma vez que podia evitar contradições que podem surgir no momento de definir o conceito, como se observa em geral nos dicionários alfabéticos. O arranjo sistemático, através de sua árvore de conceitos, permitiria a compreensão da herança conceitual de um termo, ou seja, a possível identificação das classes superordenadas e subordinadas de conceitos. Desta forma auxiliaria na compreensão do conteúdo conceitual do termo e, em determinadas circunstâncias, tornaria a própria definiçãa supérflua, pois tal arranjo acaba substituindo parte do que estaria descrito em tais definições, pelo menos no que concerne as relações de gênero e espécie.

Além da dificuldade de comunicação entre os pares, o arranjo alfabético afetava o próprio desenvolvimento científico e técnico da terminologia. A esse respeito Wüster (1974, 1981) registra a resistência dos linguistas naquele momento, e que ele chama de "competição inconsciente" entre os linguistas e a terminologia no que releva a organização sistemática dos dicionários, em detrimento da ordem alfabética. 
A proposta de Wüster não foi recebida pacificamente, não pelos engenheiros: entre estes, a organização sistemática não foi alvo de discussão. Na segunda metade do século XX tem início o debate entre os linguistas partidários do método alfabético e aqueles do método sistemático: muito estimulante, segundo ele. Quando Wüster $(1974,1981$, p. 76$)$ se refere à "competição entre os linguistas e a terminologia", isto fica claro numa carta de Schlomann, autor de um dicionário sistemático de máquinas, em que comenta a "corporação de filólogos que recusa em sua grande maioria os trabalhos lexicográficos realizados na área técnica ou os considera um disparate".

Nos anos 30 do século passado, na mesma época da TGT, engenheiros russos se envolvem também com a linguagem técnica, dando surgimento à Escola Russa de Terminologia (FELBER, 2001). Tanto na Áustria como na União Soviética os engenheiros percebem que problemas na comunicação técnico-científica eram devidas ao uso inadequado dos termos, daí a necessidade de interferência com vistas a uma padronização.

O impulso para o desenvolvimento da atividade de terminologia foi a criação do Comitê Técnico da ISO (ISO/TC 37), que contou desde sua fundação com o empenho de engenheiros e cientistas da Europa Oriental e da União Soviética.

Na União Soviética, a questão foi agravada pela presença de várias línguas das Repúblicas que a integravam, bem como da introdução de termos estrangeiros importados juntamente com a respectiva tecnologia, daí a necessidade de planejamento da língua e a consequente necessidade de normalização.

É claro que estas questões deveriam afetar outros países, mas foi entre a Áustria e a URSS que os esforços visando a solução da linguagem científica e técnica tomaram impulso, dando origem a uma nova área do saber, a Terminologia. Teorias e princípios metodológicos estavam na agenda dos fundadores desta nova área do saber na qual a Lógica é fundamental.

A abordagem sistemática esteve presente também em outra esfera da atividade humana, a saber, na atividade bibliográfica, desde Calímaco, III a.C. (MANGUEL, 1997, p. 219-220). ${ }^{4}$ A imprensa de Gutenberg impulsionou a bibliografia nacional e a segunda revolução tecnológica provocou o crescimento da bibliografia especializada, originando o conceito de Documentação, e a necessidade de um instrumento que desse conta do controle bibliográfico universal, no caso, a Classificação Decimal Universal (OTLET, 1934). A introdução da computação e o conceito de Recuperação da Informação produziram outro instrumento de

4 A ligação com a bibliografia deve-se ao fato que esta é voltada para a especialização, via de regra.

PontodeAcesso, Salvador, v. 15, n. 3, p. 184-203, dez. 2021

www.pontodeacesso.ici.ufba.br 
controle, desta vez de natureza terminológica, o tesauro, em substituição às classificações bibliográficas. Enquanto Otlet se volta para uma exposição geral sobre o Livro e Documento, é na Biblioteconomia, com Ranganathan (1967), que estão os princípios de Classificação. Sua Teoria é robusta e está cada vez mais presente na atualidade, inclusive no ambiente Web.

Assim, ambientes distintos buscam a classificação para atender a diferentes propósitos via sistematização dos termos. E desenvolvimentos teóricos recentes contribuem para o aprimoramento da Terminologia como área de pesquisa.

\title{
3 AS ABORDAGENS METODOLÓGICAS
}

De acordo com a Teoria Geral da Terminologia, o conceito é o ponto de partida para a atividade terminológica (WÜSTER, 1979, 1998).

Baldinger (apud COUTO, 2012) registra transformações que ocorrem no campo da Linguística no início do século XX, em especial no campo da semântica, a saber, dois modos de estudar o significado: a semasiologia e a onomasiologia, discussão que se mostrou frutuosa naquele momento em que também se discutia a Teoria da Linguagem, embora essa dicotomia tivesse início no século XIX. No entanto, elas são abordagens complementares: a onomasiologia considera o ângulo daquele que fala e que, portanto, precisa escolher os diferentes meios de expressão, enquanto a semasiologia aborda o problema de quem ouve, sendo este que determina o significado da palavra entre tantos outros possíveis (BALDINGER, 1966 apud FARIAS, 2013, p. 31)

Grondelaers e Geeraerts (2003, p. 69, tradução nossa) assim descrevem as duas abordagens:

\begin{abstract}
A semasiologia ... considera a palavra isolada e o modo como seus significados se manifestam, enquanto a onomasiologia olha as designações de um dado conceito, isto é, a multiplicidade de expressões que formam um conjunto. A diferença entre a semasiologia e a onomasiologia, então, equivale à diferença entre significado e nome: a semasiologia toma como ponto de partida a palavra como forma e registra os significados que podem ocorrer com aquela palavra; a onomasiologia toma como ponto de partida um conceito e investiga quais as diferentes expressões pelas quais um conceito pode ser designado ou nomeado, como tesauros, ontologias e terminologias.
\end{abstract}

$\mathrm{Na}$ abordagem semasiológica a palavra pode ser polissêmica, ou seja, o sentido se manifesta no contexto. Em diversos contextos a palavra pode manifestar vários objetos. Dito 
de outro modo, o que se tem é a relação Coisa-Palavra; é a informação semântica que pode estar associada com aquela palavra - basicamente quais os significados da palavra. A semasiologia, em outras palavras, lida com a polissemia e a definição da leitura polissêmica das palavras (GEERAERTS, 2003).

A onomasiologia parte de fora, do conceito (do objeto), e procura pela denominação que ele recebe, ao passo que a semasiologia parte de dentro, da palavra, de modo que há um paralelismo reverso entre as duas abordagens A discussão segue ainda hoje com a contribuição de pesquisadores brasileiros (COUTO, 2012).

De fato, as posições dos autores citados não são conflitantes: uma abordagem visa o conceito, e, portanto, considera a linguagem de um universo de conhecimento, a outra situa o fenômeno na língua geral. Na prática, as duas visões se complementam, dependendo dos objetivos buscados.

Duas palavras devem ser observadas: Sentido e Significado. Na semasiologia nos referimos a sentido, na onomasiologia, temos significado. Na onomasiologia, o nome/o termo - e não mais a palavra - denota, caracteriza o conceito, carrega o significado em um dado universo de conhecimento referido e, portanto, mesmo isoladamente não causa dúvida quanto a seu significado.

A base da operação dos linguistas continua sendo a palavra em suas diversas ramificações: Socioterminologia, Teoria comunicativa, Abordagem sociocognitva (CABRÉ, 2003; GAUDIN, 2005; TEMMERMAN, 2000), dentre outros. Quando desenvolvem algum trabalho prático, a ordem alfabética predomina e o método adotado no planejamento é dedutivo, enquanto na abordagem onomasiológica o método é indutivo, pois relaciona sempre um conceito a seu conceito genérico. Mas os termos 'podem adquirir um valor pedagógico ou descritivo depois de sua estruturação (GRESSER, 2010).

Os linguistas estão preocupados com as palavras da língua e com seu uso na linguagem. $\mathrm{Na}$ organização do conhecimento, o que se visa é o conceito em um sistema de conceitos. Tal sistema é ao mesmo tempo uma base de conhecimento em si mesma e também um instrumento de controle da indexação visando a representação de conteúdo.

Por vezes os linguistas tentam alguma estruturação em algum universo do conhecimento. Quando tentam uma estrutura sistemática, organizam em geral os termos por tema: método dedutivo, arbitrário por natureza. Tal abordagem não leva, em geral, a uma estrutura lógica e, portanto, a uma organização que permita, de um lado, que o usuário encontre 
o termo mais adequado a seu intento e, de outro, a formação de um banco de termos inteligente, podendo dificultar a necessidade de inclusão de futuros conceitos. O arranjo alfabético pode ser de alguma utilidade para o usuário comum, não especializado, mas inaceitável para bancos terminológicos inteligentes e ontologias.

A abordagem onomasiológica, então, é extra-linguística, ou seja, seu foco é o referente. Privilegia um universo de conhecimento e a ordem sistemática como forma mais eficaz de organização, visto que o arranjo alfabético oculta a estrutura conceitual. Ela surge com o objetivo de nomear; surge de necessidade no campo da ciência e da técnica. Quando um novo objeto - fenômeno, propriedade, instrumento .... - é observado, descoberto ou criado, busca-se nomeá-lo de modo que possa, de algum modo, realçar um aspecto/ característica/ faceta essencial. Por exemplo, "átomo", "valvopatia” e assim por diante. Nas Ciências Sociais a metáfora é um dos meios, como no exemplo "empréstimo compulsório"; no chão de fábrica, a metáfora pode ser a forma, como "árvore de natal", tradução do inglês para um conjunto de válvulas na indústria do petróleo.

$\mathrm{Na} \mathrm{CI}$, como de resto nos demais ramos do conhecimento, estes nomes já estão dados, não são objeto de investigação nem de tipificação. O que se estrutura são os conceitos denotados pelos termos. São aceitos. E TGT considera o estudo da língua do ponto de vista sincrônico (WÜSTER, 1974, 1981). Desse modo, considerações históricas sobre o significado dos termos não entram em consideração. E quando ocorrem várias expressões para nomear o mesmo objeto, então a frequência de uso é decisiva.

Dado que na ciência a precisão na comunicação é essencial, há uniformidade entre comunidades de pesquisa em relação à necessidade de padronização terminológica natural ou via recomendação de organizações internacionais como a International Standardization Organization (ISO). Esta é uma crítica dos linguistas: não é possível padronizar, ser prescritivo. Mas na Biblioteconoma/Ciência da Informação (BCI) a padronização via 'controle de vocabulário’ sempre foi um must.

\section{O CONCEITO}

Conceito é uma questão de filósofos e teóricos, mas princípios visando sua aplicação prática se dão na BCI com os classificacionistas Ranganathan e Dahlberg e eu acrescentaria o engenheiro Wüster, criador da Teoria Geral da Terminologia. Eles têm em comum o conceito 
como ponto de partida e seus elementos, a saber, a definição, o relacionamento entre os conceitos - vale dizer, o sistema de conceitos, a classificação.

As abordagens teóricas são voltadas, em linhas gerais, para o uso de instrumentos como tesauro documentário, taxonomia, dicionário especializado, ontologias e outros produtos/serviços de informação como, organização de páginas web/arquitetura da informação.

A identificação do conceito se dá via método analítico, indutivo. $\mathrm{Na}$ Teoria Geral da Terminologia o conceito, em sua origem, é uma unidade de pensamento (WÜSTER, 1974, 1981). Esta definição é revista por Dahlberg (1983): o que está na mente de um indivíduo não é necessariamente o que está na mente de outro e assim a objetividade fica prejudicada. Dahlberg (1978a) considera que o conceito é resultado da análise do referente de um domínio, isto é, ao identificar uma unidade lexical em um discurso especializado, esta remete a um dado referente e a nenhum outro, e é este que vai ser analisado e representado. Ao iniciar a análise do referente a unidade lexical deixa de ser considerada. Nesta etapa, identificam-se os atributos do referente; em um processo de abstração, os atributos comuns, essenciais, do referente tornam-se as características do conceito. O resultado da análise produz, na verdade, conhecimento do referente; então o conceito é uma unidade de conhecimento constituído pelo referente, suas características e o termo (DAHLBERG, 1978a).

As características são também conceitos e como tal devem ser analisados e definidos, e, desse modo, há relação entre o que se define e o que é definido (DAHLBERG, 1978a).

\section{AS RELAÇÕES CONCEITUAIS}

Relações entre conceitos estão na base do conhecimento. Elas "funcionam como cimento que liga conceitos na estrutura do conhecimento". Precisamos delas "para raciocinar e fazer inferências" (NA; KHOO, 2006). Elas têm sido objeto da linguística, da psicologia e das ontologias. Mas na Ciência da Informação são fundamentais pois conformam os Sistemas de Organização do Conhecimento - SKO - podendo se apresentar como nomenclaturas, sistemas de classificação, tesauros, ontologias (STOCK, 2010).

Dois são os tipos básicos de relação: lógicas e ônticas. As relações lógicas, também chamadas relações de abstração, repousam na semelhança, isto é, no fato que dois conceitos têm ao menos uma característica comum. Elas produzem relações de subordinação: verticais e horizontais. As relações ônticas produzem relações partitivas e tantas quantas possam ser 
observadas em uma comunidade de pessoas reunidas em torno de uma mesma área de conhecimento, seja científica, de negócio ou outra. Relações ônticas ocorrem entre objetos e têm despertado a atenção de pesquisadores das mais diversas áreas do conhecimento e com os mais diferentes propósitos. Enquanto as relações lógicas, abstratas, produzem hierarquias, as relações ônticas produzem relações de vários tipos e permitem modelar o mundo dos objetos de um dado universo do conhecimento contribuindo para estruturar os conceitos de modo sistêmico. De fato, tais relações conformam um sistema de organização do conhecimento.

Wüster assim classifica as relações:

- Lógicas (genérica e específica) e

- Ônticas

○ Relações de contato ou contiguidade

- Relação Todo-Parte

○ De encadeamento: predecessor

- Relação Predecessor- Sucessor

○ Relações de causalidade ou parentesco

- Relação Geracionais: Ascendente - Descendente; Filogenética

- Relação de Estágio: Ontogênica; Substâncias

Vale consultar as contribuições de Nuopponen $(1994,2006,2011)$ que expandem as relações da TGT. No entanto, conforme se observa na proposta da TGT, o resultado são sistemas parciais de conceitos, ou seja, organizam-se as classes, mas carece uma orientação para organizar todo o conjunto de classes em um todo orgânico.

Ranganathan (1967) classifica as relações também em lógicas e ônticas, como se depreende da organização do texto dos Prolegomena. Após estabelecer princípios para a atividade no Plano das Ideias (Parte E) ele apresenta o Cânone para Renque (ingl.: Array) relação horizontal, e o Cânone para Cadeia (ingl.: Chain) - relação vertical, que são formas de apresentação da relação lógica. ${ }^{5}$

As relações ônticas estão presentes na Parte R dos Prolegomena, quando Ranganathan trata da Classificação Analítico-Sintética. Ele introduz as Categorias Todo, Órgão e Constituinte (Seção RL). ${ }^{6}$ A introdução destes conceitos neste momento é esclarecedora quando se vai classificar entidades em um universo de entidades, ou seja, quando se vai estruturar

5 A ligação com a bibliografia deve-se ao fato que esta é voltada para a especialização, via de regra. 6 O texto não é uma tradução exata pois a linguagem de Ranganathan é pouco clara para o não iniciado. PontodeAcesso, Salvador, v. 15, n. 3, p. 184-203, dez. 2021 
ideias/conceitos em um universo de conhecimento. Evidentemente, a síntese a seguir prejudica a compreensão da complexidade do conjunto de relações partitivas proposto por ele, mas é esclarecedora para o que se propõe nesta comunicação.

- Todo é uma dada entidade considerada completa em universo de entidades

- Parte é um não-todo de uma dada entidade em um universo de entidades

- Porção tem o sentido de parte de um universo de entidades, mas Ranganathan prefere usar o termo 'porção' em vez do termo 'parte'.

- Órgão é uma parte funcional de uma dada entidade do universo de entidades.

Obs.: Cabe incluir sua explicação para este item. 'Os diferentes órgãos de um Todo têm em geral diferentes funções. Têm também diferentes estruturas, em geral; ou são formados ou constituídos de modos diferentes. Um órgão se distingue do Todo e de todos os seus outros órgãos. Por vezes, é separável do Todo; mas, se separado, sua função cessa imediatamente ou rapidamente depois da separação do Todo'

- Constituinte - aplica-se a uma dada entidade de um universo de entidades para uma parte típica da entidade sem função específica própria no que respeita a atividade completa, mas mantém sua individualidade... Um Constituinte não é específico de uma dada entidade do universo como qualquer de seus órgãos. Numa entidade que não seja social, o constituinte pode ser um material ou uma propriedade. Em uma entidade social é uma propriedade.

Obs.: As considerações de Ranganathan evidenciam a complexidade do que se considera "Constituinte" quando da elaboração do sistema de conceitos, visto que as decisões tomadas influenciarão as possibilidades de recuperação e/ou navegação. Dito de outro modo, os propósitos podem ser a base para a identificação do tipo de Constituinte.

- Entidade Fluida - é um desdobramento de Constituinte. Quando se tira algo de uma entidade fluida, tem-se Porção, e não parte.

- Entidade Sólida - Pode-se ter Porção quando se considera um dado conjunto de um universo de entidades. Em um universo de bicicletas, pode-se tomar "porções" - uma porção, um apanhado - como um conjunto de bicicletas de vários tipos, por exemplo. Mas quando se considera uma entidade, ela pode conter "órgãos" - tomada em seu sentido mais amplo - do ponto de vista de sua estrutura, ou Constituinte, quando se 
considera os materiais de que são feitas as "partes". Estas considerações exigem um raciocínio lógico apurado para se alcançar uma estrutura consistente.

- Entidade Social: As entidades sociais são aquelas reconhecidas como tal. Seus componentes podem ser os próprios Estados (república, monarquia socialista ou outro) ou sua estrutura interna (chefe de Estado, Presidente, Executivo, Legislativo...)

Como se pode observar, alguns tipos são complexos: incluem nuanças que, detalhadas, podem atender às exigências das ontologias.

Dahlberg $(1978 b, 2014)$ oferece igualmente, uma classificação para as relações que podem ser agrupadas em relações lógicas e ônticas:

- Relação de abstração ou genérica: ocorre entre dois conceitos quando ambos têm as mesmas características e uma delas tem uma característica a mais. Diz-se que ali existe uma implicação, do pondo de vista da Lógica. Esta relação produz uma hierarquia entre conceito e conceito subordinado, formando uma árvore hierárquica.

As relações Parte-Todo são assim desdobradas:

- Relação de partição ou relação de existência: consiste na decomposição de um todo em suas partes. Um conceito superior é dividido em seus conceitos subordinados (ou Classes e subclasses). A reunião destas partes compõe o todo, que é o item de referência.

- Relação de oposição ou de complementaridade: é a relação de contradição, contrariedade ou positivo-neutro-negativo.

Um terceiro tipo é adicionado, o qual corresponde a relação ôntica:

- Relação funcional ou sintática: relação entre os elementos de uma proposição, dependendo das valências do conceito e atividades relacionadas. Dito de outro modo, existe relação entre um objeto e atividades e/ou funções relacionadas no mundo real.

As relações partitivas têm recebido atenção de pesquisadores de áreas tão diferentes como terminologia, ciência da computação, ontologias (MADSEN; PEDERSEN; THOMSEN, 2001; MERTEN, 1992; WINSTON; CHAFFIN; HERRMANN, 1987).

Como se pode observar nas contribuições acima, as relações ônticas produzem uma teia de conceitos cuja estrutura permite maior possibilidade de um usuário encontrar um item desejado, em qualquer dos produtos/serviços de informação. Elas fornecem elementos identificados na análise do referente que estarão presentes, de algum modo, na definição.

\subsection{CATEGORIAS E O SISTEMA DE CONCEITOS}


Dentre os teóricos que buscaram desenvolver sistema de conceitos incluem-se Wüster (1974, 1981), Ranganathan (1967) e Dahlberg (1978a). Outra proposta que vale mencionar vem de um pesquisador da Escola Russa de Terminologia (KANDELAKI, 1981) completando, de alguma forma, o quadro de pesquisadores que introduzem a Categoria como instrumento para a organização das classes em um todo orgânico. A seguir, um resumo das contribuições de cada pesquisador.

Categorizar significa pensar o domínio a partir de vários aspectos (ou facetas). Assim, podemos afirmar que os objetos de um domínio podem ser considerados a partir de suas propriedades, seu material constitutivo, as ações/atividades que podem ser feitas sobre ele, os produtos ou materiais daí resultantes e assim por diante. Elas são utilizadas para a ordenação dos conceitos, mas no nível do referente, do extralinguístico (CAMPOS; GOMES, 2008).

Nos procedimentos de elaboração de modelos de domínios, as relações categoriais são fundamentais, pois permitem uma primeira estruturação do conceito no interior de um domínio. Categorias possibilitam que o modelizador chegue a qualquer domínio e consiga estabelecer uma primeira ordenação. Elas possibilitam a identificação dos referentes no interior de um domínio (GOMES; CAMPOS, 2019).

No nível de representação, categorias são classes de grande abrangência em um domínio, acima das quais não se pode colocar qualquer conceito. Como Dahlberg (1978a) afirma "as categorias fornecem ao mesmo tempo os esqueletos, os ossos e tendões para estruturar todo o conhecimento".

Para conseguir o 'mais elevado nível que pudesse abranger as inúmeras classes', Ranganathan (1967) chegou às Categorias Fundamentais: Personalidade, Matéria, Energia, Espaço e Tempo - PMEST, claramente a partir das categorias de Aristóteles. Elas estão organizadas do mais concreto para o mais abstrato. Espaço e Tempo são de fácil entendimento, Energia compreende atividades, processos; Matéria refere-se ao material de que as coisas são feitas, ou constituídas; e Personalidade - resume ele - "não é isso, não é isso", ou seja, nenhuma das outras categorias. As Categorias Fundamentais permitem organizar classes de conceitos de áreas científicas bem como de áreas de conhecimento prático, comum.

Igualmente com base em Aristóteles, e bastante próximo do PMEST, Dahlberg (1978b) introduz a Relação Categorial Formal que pode ser adotada para a organização de um sistema de conceitos: Entidades (Fenômenos, Objetos gerais imateriais, Objetos materiais); 
Propriedades (Quantidade, Qualidade, Comparação); Atividades (Operações, Estados, Processos); Dimensões (Período de tempo, Posições, Lugar no espaço). Além disso, Dahlberg introduz outra proposta: os Sistematizadores (ingl. Systematifiers) para categorizar um universo de conhecimento científico, de acordo com a natureza desse conhecimento (DAHLBERG, 1982). Eles estão agrupados em nove classes, a saber:

1) Teoria e princípios gerais: aspectos teóricos de uma área específica, natureza e essência do objeto do sistema;

2) Objeto ou objetos: descrição do(s) objeto(s) e sua organização: unidades, complexos, organismos; suas partes;

3) Aplicação da metodologia e da tecnologia em uma área: atividades e processos;

4, 5 e 6) As categorias 4-6 identificam aspectos particulares das categorias fundamentais, a saber: fenômenos e formas especiais;

7) Influências externas exercidas no objeto (do externo para o interno);

8) Aplicações de uma área, particularmente seus métodos para outras áreas (influência do interno para o externo); e

9) “Ambiente” de uma área: suas pessoas, organizações, pedagogia e didática, atividades de documentação, informação e comunicação (“disseminação").

Vale ainda, neste quesito das categorias, citar Kandelaki ${ }^{7}$ (1981), pesquisador da Escola Russa de Terminologia, Escola que mantém, a nosso ver, equilíbrio entre as questões da língua e a classificação (DANILENKO, 2001; LOTTE, 1981; VAKULENKO, 2014). Para Kandelaki, o sistema de conceitos constitui a teoria, a ciência (seu conteúdo em categorias, uma parte delas). As categorias estão assim distribuídas:
Categoria dos objetos
Categoria dos processos
Categoria dos estados
Categoria dos regimes

\footnotetext{
7 O texto original foi publicado em 1970. Há uma tradução em francês, adotada aqui (1981, e em catalão, em uma seleção organizada por M. T. Cabré, publicada em 1996. 


\author{
Categoria das características \\ Categoria das grandezas \\ Categoria das unidades de medida \\ Categoria das ciências e ramos da ciência \\ Categoria das profissões e ocupações
}

Com exceção das duas últimas categorias, as demais guardam algum paralelo com as propostas categoriais citadas acima.

\title{
6 PERSPECTIVAS FUTURAS
}

O estudo dos termos é um processo cognitivo e visa princípios para o sistema de conceitos de um dado universo do conhecimento. A Terminologia sistemática é, assim, um importante meio para planejamento e realização de múltiplas atividades de pesquisa e aplicação.

Quando os linguistas tomam conhecimento da TGT, quatro ou cinco décadas depois de seu surgimento, o aspecto sistemático foi relegado. $O$ foco de pesquisa, para aqueles pesquisadores, além das questões linguísticas, é a comunicação, o discurso. Tal abordagem não favorece o desenvolvimento de ontologias e de bases de conhecimento. Verifica-se, no século XXI, uma volta à TGT bem como propostas de revisão das normas internacionais para Terminologia (PICHT, 2007, 2011; ROCHE, 2005, 2007, 2012) e a volta à onomasiologia como adequada à construção de banco de termos inteligente.

A Teoria da Classificação com sua aplicação à construção de bancos do conhecimento tem recebido atenção de pesquisadores das mais diversas áreas sobre os princípios que a fundamentam. E ficam evidentes aspectos teóricos comuns à Terminologia. A abordagem onomasiológica é adotada na constituição de bancos de termos para apoiar serviços de informação/recuperação/navegação.

A relação entre os dois domínios é evidente. Um aspecto importante a ressaltar é o estudo das relações, tanto na CI como na Terminologia sistemática. Elas são úteis para a estruturação dos conceitos em um dado domínio e também para as ontologias. As predicações verdadeiras expressas na definição fornecem os elementos para a formalização, ou seja, para a manipulação pelo computador. 
Face ao exposto aqui sobre as contribuições dos classificacionistas, permanece a pergunta: existe a perspectiva de cooperação entre pesquisas de Terminologia e de Ciência da Informação como percebeu Wüster? Ou a Terminologia Sistemática, como disciplina, é campo de pesquisa da Ciência da Informação?

\section{REFERÊNCIAS}

AITCHISON, J. Practical application of a Facet Classification, with special reference to the English Electric faceted classification of Engineering. In: BAKEWELL, K. G, B. (ed.). Classification for information retrieval. London: Bingley, 1968. p. 55-56.

BREKKE, M.; ANDERSEN, O.; DAHL, T.; MYKING, J. (ed.). Applications and implications of current LSP research. In: EUROPEAN SYMPOSIUM ON LSP, 9., 1994. Proceedings [...]. Bergen, Fagbokforlaget, 1994. v. II, p. 532-539. Disponível em: http://lipas.uwasa.fi/ atn/papers/artikkelit/LinkedDocuments/Nuopponen_Causal_LSP94.pdf Acesso em: 12 jan. 2019.

CABRÉ, M. T. Theories of terminology. Terminology, v. 9, n. 2, p. 163-199, 2003.

CAMPO, A. The reception of Eugen Wüster's work and the development of Terminology. 2012. Tese (Doutorado em Filosofia) - Université de Montréal. Disponível em: https://papyrus.bib.umontreal.ca/xmlui/bitstream/handle/1866/9198/Campo_Angela_2012_th ese.pdf. Acesso em 12 nov. 2017.

CAMPOS, M. L. A; GOMES. H. E. G. Taxonomia e classificação: o princípio da categorização. DataGramaZero, v. 9. n. 4, artigo 01, 2008. Disponível em: https://brapci.inf.br/index.php/res/v/6615 Acesso em 03 abr. 2009.

COUTO, H. H. Onomasiologia e semasiologia revisitadas pela ecolinguística. Revista de Estudos Linguísticos, v. 20, n. 2, p. 183-210, 2012. Disponível em: http://periodicos.letras.ufmg.br/index.php/relin/article/view/2748 Acesso em 10 nov. 2020.

DAHLBERG, I. A referent-oriented, analytical concept theory for Interconcept.

International Classification, v. 5, n. 3, p. 122-151, 1978a.

DAHLBERG, I. Ontical structure and universal classification. Bangalore: Sarada Ranganathan Endowmente for Library Science, 1978b.

DAHLBERG, I. Wissensorganisation: Entwicklung, Aufgabe, Anwendung, Zukunft. Würzburg: Ergon Verlag, 2014. 
DAHLBERG, I. Information Coding Classification - principles, structure and application possibilities. International Classification, v. 9, n. 2, p. 87-93, 1982. Disponível em: https://www.ergon-verlag.de/isko_ko/downloads/ic_9_1982_2_e.pdf Acesso em: 05 mar 2015.

DAHLBERG, I. Terminological definitions: characteristics and demands. In: COLLOQUE INTERNATIONAL DE TERMINOLOGIE. 1982, Québec. Actes [...]. Québec: Université Laval, 1982. p. 15-83.

DANILENKO, V. P. Sobre la posición de la terminologia cienífica en el sistema léxico de la lengua.

In: CABRÉ, M. T. (org.) Textos de terninólogos de la Escuela Rusa. Barcelona: IULA, 2001. p. 19-28.

FARIAS, V. S. Sobre a definição lexicográfica e seus problemas fundamentais para uma teoria geral dos mecanismos exploratórios em dicionários semasiológicos. 2013. Tese (Doutorado em Letras) - Universidade Federal do Rio Grande do Sul, Porto Alegre, 2013. Disponível em: https://www.lume.ufrgs.br/handle/10183/90167 Acesso em: 3 mar. 2021.

FELBER, H. Prefàcio In: CABRÉ et al. (ed.). Textos de terminólogos de la Escuela Rusa. Barcelona: Documenta Universitaria, 2001. p. 15-17.

GAUDIN, F. La Sociotérminologie. Langages, n. 157, p. 80-92, 2005. Disponível em: https://www.persee.fr/doc/lgge_0458-726x_2005_num_39_157_976. Acesso em 03 março 2021.

GEERAERTS, D. Meaning and definition. In: STERKENBURG, P. I. A Practical Guide to Lexicography. Leiden: John Benjamin, 2003. p. 83-93. Disponível em: http://wwwling.arts.kuleuven.be/qlvl/PDFPublications/03Meaninganddefinition.pdf. Acesso em: 02 jun. 2020.

GOMES, H. E. Comissões nacionais e internacionais de terminologia. In: CONGRESSO REGIONAL SOBRE DOCUMENTAÇÃO, 2.; REUNIÃO DA FID/CLA. 9. 1970, Rio de Janeiro. Anais [...]. Rio de Janeiro: IBBD, 1970. p. 382-387.

GOMES, H. E.; CAMPOS, M. L. A. Systematic aspects of terminology. Meta, v. 41, n. 2, p. 247-254, 1996. Disponível em: https://www.erudit.org/fr/revues/meta/1996-v41-n2meta179/002939ar.pdf Acesso em: 20 set. 2021.

GOMES, H. E.; CAMPOS, M. L. A. A Organização do conhecimento na Web: contribuições de Shiyali Ramamrita Ranganathan e de Ingetraut Dahlberg. Niterói: IACSUFF, 2019. (Cadernos acadêmicos, 1)

GRESSER. J.-Y. Ontologies des risques financiers. In: ROCHE, C. (ed.). CONFÉRENCE TERMINOLOGIE \& ONTOLOGIE: THÉORIES ET APPLICATIONS, TOTh. 2010, France. Actes [...] França: Institut Porphyre, 2010. p. 153-173. Disponível em: https://hal.archivesouvertes.fr/hal-01354936/document Acesso em 3 de jun. de 2020. 
GRONDELAERS, S.: GEERAERTS, D. Towards a pragmatic model of cognitive onomasiology. In: CUYCKENS, H.; DIRVEN, R.; TAYLOR, J. R. (ed.). (ed.). Cognitive approaches to lexical semantics. Berlin: Gruyter Mounton, 2003. Disponível em: https://www.degruyter.com/document/doi/10.1515/9783110219074.67/html. Acesso em: 20 jun. 2020.

KANDELAKI, T. L. Les sens des termes et les systèmes de sens des terminologies scientifiques et techniques. In: RONDEAU, G.; FELBER, H. (org.) Textes choisis de Terminologie. Québec: GIRSTERM: Université Laval, 1981. p. 135-184.

LOTTE, D. S. Formation du système des termes scientifiques et techniques. In: RONDEAU, G.; FELBER, H. (org.) Textes choisis de terminologie. Québec: GIRSTERM: Université Laval, 1981. p. 3-53.

MADSEN, B. N.; PEDERSEN, B. S.; THOMSEN, H. E. Defining semantic relations for OntoQuery. In: Ontology-based Interpretation of Noun Phrases. 2001. Disponível em: https://research.cbs.dk/en/publications/defining-semantic-relations-for-ontoquery. Acesso em: 12 maio 2021.

MERTEN, P. Apport des relations notionnelles à la description terminologique. In: SYMPOSIUM TERMNET Tama`92, 2., Vienne. Proceedings [...]. Viena, TermNet. 1992. p. 203-228. Terminology in advanced microcomputer applications.

MANGUEL, A. Uma História da leitura. São Paulo: Companhia das Letras, 1997.

NA, J. C.; KHOO, C. S. G. Semantic relations in information science. Annual Review of Information Science and Technology, v. 40, n. 1, p. 157-228, 2006. Disponível em: https://doi.org/10.1002/aris.1440400112. Acesso em: 15 maio 2021.

NUOPPONEN, A. Wüster revisited: on causal concept relationships and causal concept systems. In:

NUOPPONEN, A. A model for structuring concept system of activity. TSTT 2006 Beigin, 2006. Disponível em:

http://lipas.uwasa.fi/ atn/papers/artikkelit/LinkedDocuments/Nuopponen_Activity_TSTT06.p df Acesso em 13 fev. 2020.

NUOPPONEN, A. Methods of concept analysis - tools for systematic concept analysis - Pt 3 of 3. LSP Journal v. 2, n.1, p. 4-15, 2011. Disponível em: https://rauli.cbs.dk/index.php/lspcog/article/view/3302. Acesso em 04 jan. 2018.

OTLET, P. Traité de documentation: le livre sur le livre, théorie et pratique. Bruxelles: Mundaneum, 1934.

PICHT, H, Terminology yesterday, today and tomorrow. Journal of Terminology Science and Research, v. 18, p. 5-13, 2007. 
PICHT, H. The science of terminology: history and evolution. Terminologija, n. 18, 2011. Vilnius, Lituânia, p. 6-26, 2011. Disponível em: https://www.ceeol.com/search/articledetail?id=563193. Acesso em: 13 fev. 2020.

RANGANATHAN, S. R. Prolegomena to Library classification. Bombay: Asia Publishing House, 1967. 638 p.

ROCHE, C. Terminologie et ontologie. Langages, n. 157, p. 48-62, 2005. Disponível em: https://www.cairn.info/revue-langages-2005-1-page-48.htm, Acesso em: 12 jan. 2019.

ROCHE, C. Le terme et le concept: fondements d'une ontoterminologie. In: CONFÉRENCE TERMINOLOGIE \& ONTOLOGIE: THÉORIES ET APPLICATIONS, TOTh. 2007, France. Actes [...]. Annecy, France. 2007. p. 1-22. Disponível em: http://christopheroche.fr/Bibliographie/2007/Ontoterminologie_TOTh_2007.pdf Acesso em: 15 jan. 2019.

ROCHE, C. Should Terminology principles be re-examined? In: AGUADO DE CEA et al. (ed.) CONFERENCE TERMINOLOGY OF KNOWLEDGE ENGINEERING, 10., 2012, Madrid. Proceedings [...]. Madrid, Spain. 2012. p. 17-32. Disponível em: https://arxiv.org/ftp/arxiv/papers/1609/1609.05170.pdf Acesso em: 15 mar. 2020.

STOCK, W. G. Concepts and semantic relations in information Science. Journal of the American Society for Information Science and Technology, v. 61, n. 10, p. 1951-1969, 2010. Disponível em: https://www.researchgate.net/publication/220433962_Concepts_and_Semantic_Relations_in_ Information_Science. Acesso em: 13 jan. 2019.

TEMMERMAN, R. A realist theory of terminology: the sociocognitive. Terminologies nouvelles, v. 21, p. 58-64. 2000. Disponível em: https://www.academia.edu/31325740/Une_th\%C3\%A9orie_r\%C3\%A9aliste_de_la_terminol ogie_le_sociocognitivisme. Acesso em: 21 fev. 2019

VAKULENKO, M. Term and terminology: basic approaches, definition and investigation methods (East-European perspective). Terminology Science \& Research, v. 24, 2014. Disponível em: https://www.researchgate.net/publication/336605560_Term_and_terminology_basic_approac hes_definitions_and_investigation_methods_EastermEuropean_perspective_In_Terminology_Science_Research Acesso em: 15 fev. 2020.

WINSTON, M.; CHAFFIN, R.; HERRMANN, D. A taxonomy of part-whole relations. Cognitive Sciences, v. 11, p. 417-444, 1987. Disponível em: https://www.researchgate.net/publication/245104866_A_Taxonomy_of_PartWhole_Relationships/link/5693c52608ae425c6895ff14/download. Acesso em: 16 mar. 2020.

WÜSTER, E. Introducción a la Teoria General de la Terminologia y la Lexicografia Terminológica. Barcelona: IULA, 1998.

WÜSTER, E. L'Etude scientifique générale de la terminologie, zone frontalière entre la linguistique, la logique, l'ontologie, l'informatique et les sciences des choses. In: 
PontodeAcesso: Revista do Instituto de Ciência da Informação da UFBA DOI: https://doi.org/10.9771/rpa.v15i3.47464

RONDEAU, G.; FELBER, H. (org.) Textes choisis de Terminologie. Québec: GIRSTERM: Université Laval, 1981. p. 55-114. 